\title{
The Influence of Gender Differences on
}

\section{Jordanian Second Grade Pupils' Spelling in English}

\author{
Na'ela Al-Mahdawi
}

\author{
Yarmouk University, Jordan
}

Na'ela AL-Mahdawi, a PhD candidate in TEFL at the Department of Curriculum and Instruction at Yarmouk University, Jordan, is currently a teacher at the Ministry of Education in Jordan. She won Queen Rania Award for Distinguished Teacher in 2012. Her research interests are ELT and strategic teaching

\begin{abstract}
This study investigated The Influence of Gender Differences on Jordanian Second Grade Pupils' Spelling in English.The sample consisted of two second grade sections from Douqarah Co-educational Basic School ( $N=33$ male students and 29 female students) in the second semester of the academic year. 25 words spelling test was administered to identify differences in spelling skills. There were statistically significant differences between students' scores on the spelling achievement test due gender, in favor of the females. In light of these results, some recommendations were suggested.
\end{abstract}

Keywords- Gender, spelling, Jordanian second grade students, teaching techniques.

\section{INTRODUCTION}

Despite the numbers of studies examining gender differences in EFL skills, there is a need for more studies shedding light on this so as to help EFL teachers, especially in the basic grades, adapt their teaching methods to eliminate these differences in a way that may help them achieve what they pursue, which is to provide rich learning experiences for students from both genders. Several studies have documented the variances in language acquisition due to gender, while others indicated that there are no statistically significant differences in language skills due to gender. For example, Allred (1990) has documented in one study that female students reported higher scores in spelling achievement and that this was a major finding in most of the previous studies that examined gender differences. Affirming this fact, AL-Omari (1997) investigated gender differences in spelling acquisition between male and female Jordanian students, and concluded that a significant difference, in favor of females, was established. By contrast, Woods (2016) reported in her study no statistically significant differences in students' writing skills due to gender, while Burušić and Šerić (2015) reported in their review study of previous studies examining gender differences in language skills that the results of related previous studies were not decisive about the existence of gender differences in language skills. This dictates the need for more studies examining these variances, especially among EFL students in the basic level, and this what has urged the researcher to perform this study as she found paucity in previous studies after a thorough review of previous related studies.

Males and females have been noticed to differ in language learning strategy use. One of the explanations underlying this is the differences in personality style. Thus, each sex has been noticed to adhere to specific personality style which, in turn, affects the kind of strategy being utilized. Oxford (1993) stated that an analytic field independent learner (probably a male student) usually utilized strategies of logic, such as deductive reasoning, whereas a global, field-dependent learner (often a female student) chooses strategies of searching for the main idea and intuitively guessing from a multiple clues when some pieces of information are missing. These generalizations cannot be understood without recourse to brain hemisphericity. Right hemisphere and left hemisphere deal with the language differently. The left hemisphere is in charge of interpreting the meaning of words, whereas the right hemisphere deals with verbal tones, patterns and musical qualities of the language. Males usually process the language through the left hemispheric, analytic mode, while females often process the language through the right hemisphere, global mode or through an integration of the left and right hemispheric modes (Oxford, 1993).

In a different point of view, Woods (2016) asserts that there are no statistically significant differences in students' writing skills due to gender and explained that the previous educational literature lacks conclusive evidences affirming the generic differences in students' ability in language skills, including writing. 
While Both Burušić and Šerić (2015) contend that there previous educational literature examining the role of gender in explaining differences in some personal characteristics such as preferred learning styles and language achievement are not decisive in giving evidences supporting one perspective on the other as the results obtained from previous studies were relatively contradictory and this requires more examination from the authors' point of view to verify the presence of gender differences in students various language skills, including spelling, and this what this study seeks as the main objective of the study is to investigate whether there were differences in second grade students achievement due to gender.

This study is expected to present results that may explain gender differences in spelling skills, an important language skill in English. This may be helpful for both teachers and parents to consider these differences when working students from both genders.

\section{Question of the Study}

The study attempted to answer the following main question:

Are there any significant differences $(\alpha=0.05)$ in second grade pupils' mean scores in the spelling test due to gender?

\section{Definitions of Terms}

Spelling: The process of encoding units of sound to written symbols, to write the words the pupils heard as they should be written, i.e. to write without missing or adding any letters as dictionary writes. Operationally it is the students' scores in English on the spelling test constructed by the researcher.

Gender: all males and females that are studying in the basic second grade.

\section{REVIEW OF RELATED LITERATURE}

These are some research that examining gender differences in language learning. The focus of attention was directed toward studying learning strategies in general with a reference to gender.

Allred (1990) investigated a study about gender differences in spelling achievement in elementary schools. The sample of the study consisted of male and female students from grade 1 to grade 6 . The results of the study indicated that female students in elementary schools spell significantly better than male students at all grade levels.

Kaylani (1995) investigated the effect of gender and motivation on the language learning strategy use of Jordanian successful and unsuccessful English language learners. The survey method was used in the form of questionnaires and interviews to collect data on a sample of 255 twelfth grade high school students in Amman. The findings revealed that female students in the sample used compensation, cognitive, affective and memory strategies to a significantly higher degree than male students. Demographic factors other than sex, such as school type and school track, explained fewer significant differences between gender groups.

Liston (1996) investigated possible gender differences in language learning strategy use among students of English as a second language. He found that there was no significant statistical difference between male and female participants in the sample. It was concluded that the study showed no differences in language learning strategy use as differentiated by gender.

AL-Omari (1997) examined gender variation in the use of different language learning strategies utilized by the eleventh graders. The sample of the study consisted of 58 males and 54 females enrolled in the scientific stream. 42 Males and 46 females enrolled in the literary stream. The main instrument was a questionnaire which required the respondents to indicate the degree with which they use certain language learning strategies. The results of the study indicated that: there was a variation between males and females in the use of certain language learning strategies, males have surpassed females in the use of cognitive and social strategies.

Hruska (1999) investigated bilingualism, gender and friendship on a study that focused on English as second language learners in an English mainstream kindergarten classroom. The findings indicated that boys dominated public discussions and constructed thems elves as superior to girls.

Rios (2000) investigated gender differences in spelling achievement between male and female students. The sample of the study included (20) male and (20) female secondary school students. For data collection, a spelling achievement test was developed by the researcher. The results of the study indicated that there were differences, but not statistically significant, due to gender, in favor of females, in spelling achievement.

AL-Otaibi (2004) examined the language learning strategies of Saudi EFL students in an intensive English program. The study sought to give an account of the type and frequency of strategy use among these students. It was also conducted to examine the relationship between strategy use and certain factors such as language proficiency level, gender and motivation. The findings indicated that female participants utilized a more active approach to language learning, and was more inclined to communicate with English speakers than males. The findings from the group interviews also showed greater female strategy use, especially out of class strategies. Baniabdelarhman (2004) investigated the effectiveness of word boxes on Jordanian EFL fifth grade students. He 
found that no significant interaction between the teaching technique of spelling and gender. He revealed that there was no significant difference in students' spelling scores due to gender. He found a significant difference between students' scores in spelling due to the technique of instruction and that students spelling scores in the word boxes were significantly higher than the student's scores in the traditional method. Allred (2015) examined gender differences in spelling achievement among male and female students from grade 1 to grade 6 . The sample of the study consisted of (242) male and female students whom their spelling performances on standardized test were compared in addition to administrating a spelling achievement test developed by the researcher. The results of the study indicated that there were statistically significant differences in the spelling performance on standardized test and the spelling achievement test developed by the researcher for the objectives of the study, in favor of female students; making it plausible to conclude that girls spell better than boys.

Both Burušić and Šerić (2015) reviewed previous studies examining gender differences in some individual attributes such as learning styles, language acquisition and self- esteem. The study reviewed scientific and educational journal and used content analysis design for obtaining the results of the study. The results of the study indicated that there were statistically significant differences due to gender, in favor of females, in language acquisition abilities such as speech skills, reading skills and writing skills. The study also concluded that these differences did not vary across age.
In the same line of research, Cobb-Clark and Moschion (2015) investigated gender gaps in early educational achievement. The sample of the study consisted of (3174) third grade students participating in one national study investigating numeracy and reading skills. For data collection, a reading and numeracy results for the sample of the study were obtained from the national study data. The results of the study indicated that third grade females outperformed males in both numeracy and reading skills, affirming the assumption that female students are better in both numeracy and reading skills.

Woods (2016) investigated gender differences in writing skills among American students. The sample of the study consisted of (309) third and fourth graders selected from various public schools in the USA. For data collection, a writing achievement test was administrated to the students. It was found that there were no statistically significant differences due to gender in students writing skills.

\section{Subjects of the Study}

The subjects of this study consisted of two second grade sections from Douqarah Co-educational Basic School in the first semester of the academic year 2016-2017. The first section consisted of 17 male students and 14 female students. The second section consisted of 16 male students and 15 female students. The age of the students was between 7 and 8 , and they all had 1 year of experience in English language learning.

Table.1: Distribution of the Sample of the Study according to Gender

\begin{tabular}{|l|l|c|c|}
\hline Variable & & Frequency & Percent \\
\hline \multirow{3}{*}{ Gender } & Male & 33 & 53.2 \\
& Female & 29 & 46.8 \\
\cline { 2 - 4 } & Total & 62 & 100.0 \\
\hline
\end{tabular}

\section{Instrument of the Study}

The researcher developed a spelling achievement test. It was administered to the subjects of the study at the end of the second semester. The raw scores of the students' achievement test were used as instrument of this study. The spelling test consisted of 25 words. The researcher corrected the test. Four points were given to each correct word and zero for the incorrect one. The total score for the spelling test was 100 .

\section{Data Analysis}

Descriptive statistics consisting of means and standard deviations and T-test was used to analyze the data of the study.

\section{Findings of the Study}

Table.1: shows group statistics based on their gender.

Group Statistics

\begin{tabular}{|c|c|c|c|c|c|c|c|}
\hline & Sex & $\mathrm{N}$ & Mean & $\begin{array}{c}\text { Std. } \\
\text { Deviation }\end{array}$ & $\mathrm{t}$ & Sig. (2- \\
tailed)
\end{tabular}


Table (2) shows the results of students' spelling achievement test as students' means and standard deviations were computed based on their scores on the spelling achievement test.

Table.2: Means and SD for students in the spelling achievement test

\begin{tabular}{|c|c|c|}
\hline Sex & Mean & Std. Deviation \\
\hline Male & 78.52 & 13.426 \\
\hline Female & 86.41 & 13.021 \\
\hline
\end{tabular}

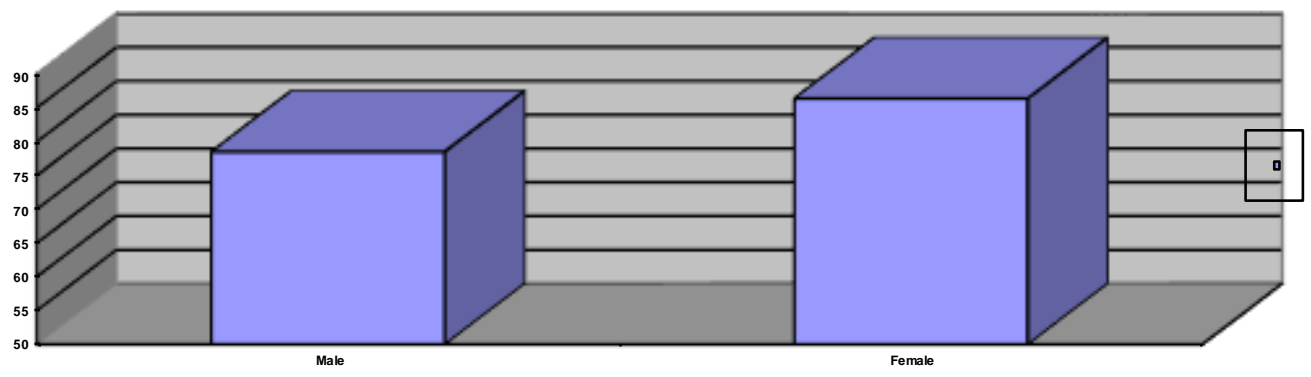

Fig: shows means of male and female

Figure (1) shows that female students outperformed male students on the spelling achievement test as the means scores of male students was $(M=78.52)$ while it was higher for female students $(M=86.41)$ and this confirms the results found in this study.

\section{DISCUSSION}

The results of the study showed that there are statistically significant differences in spelling test scores due to the gender, in favor of females. Findings from decades of research concerning gender differences in general indicated that males and females differ in many aspects. Females are superior to males in verbal ability. Girls begin to talk and to use sentences and words earlier than boys. They also speak more clearly, read earlier and achieve more scores than boys in tests of spelling and grammar. Developmentally, girls appear to surpass boys in verbal performance at the ages of two of three, but for the most part there are few gender differences during childhood. Gender differences increase during the age of eleven and these differences are more apt to increase in high school and possibly beyond. This kind of superiority of girls increases not only at relatively simple verbal tasks such as spelling, but also at more complex tasks such as analogies and creative writing (Gage and Berliner- cited in AL-Omari; 1997).

Other studies such the one by Woods (2016) contradicts this view by claiming that the differences in language skills between boys and girls cannot be always attributed to gender; as other variables come to scene such as parents' educational level and quality of teaching methods employed by teachers in addition to the socioeconomic family level. Although these factors may not be decisive in explaining differences in students spelling achievement, they may be viable in the context of this study.

The results of the study about gender support AL-Otaibi's findings (2004) that females are better in learning English language than males. The results support Allred's findings (1990) that female students in elementary schools spell significantly better than boys at all grade levels. Kaylani's findings (1995) also revealed that female students used compensation, cognitive, affective and memory strategies to significantly higher degree than male students. Affirming this, Cobb-Clark and Moschion study (2015) in the USA indicated that third grade female students outperformed male students in numeracy and reading skills, affirming the assumption that female students are better in both numeracy and reading skills. But, a remark worth mentioning is that the researchers were very cautious in attributing these differences to the genic factors; indicating at the same time that there is a need verify the presence of these differences.

On the other hand, other studies found that males surpass females in learning language such as Hruska's study (1999) which revealed that males dominated public discussions and constructed themselves as superior to girls; and AL-Omari's (1997) findings that indicated that males surpassed females in the use of certain language strategies such as memorization, guessing, asking for clarification and cognitive strategies. Whereas Liston's (1996), Joseph's (2000a; 2000b) and Baniabdelarhman's (2004) findings concluded that there were no significant differences between males and females in learning language based on Piaget's theory of cognitive development. According to Piagets' theory of cognitive development, males and females acquire any 
given language in the same way and at the same age and pass thorough the same stages. This means that language acquisition is not affected by the sex of the students if they live in the same situation. (Melhem, 2004, in Arabic).

\section{RECOMMENDATIONS}

1. Further research that examines gender differences among older students would be beneficial as the results obtained from these future studies may support the findings reported in this study.

2. Further research that examines gender differences in other geographical regions would be beneficial.

\section{REFERENCES}

[1] Allred, R.A (1990). Gender Differences in Spelling Achievement in Grade 1 through 6. Journal of Educational Research, 83, 187-193.

[2] Allred, Ruel (2015). Gender Differences in Spelling Achievement in Grades 1 through 6. The Journal of Educational Research, 83(4), 187-193.

[3] AL-Omari,Omaima (1997).Gender Differences in Using English Language Learning Strategies by Eleventh Graders in Jordan.Unpublished Master Thesis, Yarmouk University, Irbid, Jordan.

[4] AL-Otaibi,Gazi N. (2004).Language learning strategy use among Saudi EFL students and its relationship to language proficiency level, gender and motivation. Dissertation Abstracts International, 65 (04), 1283. (AAC No.3129188).

[5] Baniabdelrahman, Abdallah (2004). The Effectiveness of the Use of word Boxes Instruction on the Spelling Performance of EFL Fifth Grade Students. Abhath AL- Yarmouk "Humanities and social Sciences Series" 20, (4B), 297-314.

[6] Burušić Josip \& Šerić, Maja (2015). Girls' and Boys' Achievements Differences in the School Context: An Overview of Possible Explanations. Croatian Journal of Education, 17 (4), 137-173.

[7] Cobb-Clark, Deborah \& Moschion, Julie ( 2015). Gender Gaps in Early Educational Achievement. IZA Discussion Paper No. 9535, 1-50.

[8] Hruska, Barbara Lynne (1999).Bilingualism, Gender, and Friendship: Constructing Second Language Learners in a Mainstream Kindergarten. Dissertation Abstracts International, 60 (02), 313. (AAC No.9920613).

[9] Kaylani, Cora T. (1995).The Influence of Gender And Motivation on The Language Strategy Use of Successful And Unsuccessful English Language Learners in Jordan. Dissertation Abstracts International, 56 (05), 1694. (AAC No.9529133).

[10] Liston, Guymchael (1996).Gender Differences in Language Learning Strategy Use (ESL).
Dissertation Abstracts International, 34 (01), 25.(AAC No. 1375391).

[11] Melhem, M. Sami (2004). Growth Psychology ( Human life cycle). Dar AL Fiker, Amman, Jordan.

[12] Oxford, Rebecca, L. (1993).Language Learning Strategies In a Nutshell: Update and ESL suggestion .TESOL Journal, 2, (2), pp.18-22

[13] Rios, Daisy (2000). Gender Differences in Spelling Achievement. Unpublished MA thesis, Kean University, USA.

[14] Woods, Laurel (2016). Examining Gender Differences in Writing Skill with Latent Factor Modeling. Unpublished MA thesis, University of Washington, USA. 